\title{
Text to Ideology or Text to Party Status?*
}

\author{
Graeme Hirst, Yaroslav Riabinin, Jory Graham, and Magali Boizot-Roche \\ Department of Computer Science, University of Toronto, \\ Toronto, Canada M5S $3 G 4$
}

\begin{abstract}
A number of recent papers have used support-vector machines with word features to classify political texts - in particular, legislative speech - by ideology. Our own work on this topic led us to hypothesize that such classifiers are sensitive not to expressions of ideology but rather to expressions of attack and defence, opposition and government. We test this hypothesis by training on one parliament and testing on another in which party roles have been interchanged, and we find that the performance of the classifier completely disintegrates. Moreover, some features that are indicative of each party "swap sides" with the change of government. And combining ideologically inconsistent opposition parties together in the classifier does not in most cases seriously degrade its performance. Our results suggest that the language of attack and defence, of government and opposition, dominates and confounds any sensitivity to ideology in these kinds of classifiers.
\end{abstract}

Keywords: Political texts, classification by ideology, SVMs, bag-of-words, experimental confounds, LIWC.

\section{Introduction}

There have been a number of attempts recently to develop methods to automatically determine the ideological position of a political text. For example, one might wish to take a newspaper editorial or a blog and classify it as socialist, conservative, or Green. In practice, much of the research has taken speeches by members of a legislature (such as the U.S. Congress or the European Parliament) as the text to be classified and indicators such as party membership or legislative voting patterns as a proxy for ideology (indeed, Yu et al (2008) use the terms party classifier and ideology classifier almost interchangeably); thus the problem becomes one of predicting one of these indicators from speech. One might expect, a priori, that methods based solely on the vocabulary used in a text would not be effective, because the members of a legislature, regardless of ideology, are all discussing the same topics - e.g., the legislation before them or the issues of the day - and hence would all be using the same topicderived vocabulary (Mullen and Malouf 2006). The ideology expressed in a text would

\footnotetext{
"This is a slightly extended version of "Party status as a confound in the automatic classification of political text" by Graeme Hirst, Yaroslav Riabinin, and Jory Graham, Proceedings, 10th International Conference on Statistical Analysis of Textual Data (JADT 2010), Rome, June 2010. This work is financially supported by the Natural Sciences and Engineering Research Council of Canada.
} 
thus be apparent only at the sentence- and text-meaning levels. Nonetheless, one might hypothesize that different ideological frameworks lead to sufficiently different ways of talking about a topic that vocabulary can be a discriminating feature (Lin et al 2006). And indeed, several studies have obtained notable results merely from classification by support-vector machines (SVMs) with words as features ("bag-ofwords classification").

For example, Thomas et al (2006) examined speeches made by members of the U.S. House of Representatives to try to determine whether each speaker supported or opposed the proposed legislation under discussion. They combined bag-of-words text classification by SVMs with textual information about each speaker's agreement or disagreement with other speakers, obtaining an accuracy of around $70 \%$ (the majority baseline was 58\%). Greene (2007) obtained an improved accuracy of over $74 \%$ on the same task by annotating each word with its grammatical relation from a dependency parse. Jiang and Argamon (2008), on the related task of classifying political blogs as liberal or conservative, improved results over using word features of the whole text by first trying to identify subjective sentences and the expressions of opinion that they contain, and then limiting the features to those parts of the text.

Diermeier et al (2007) used SVMs with bag-of-words features to classify members of the U.S. Senate by ideology, labelling each speaker as a liberal or a conservative, and achieved up to $94 \%$ accuracy. However, in these experiments, the authors focused on "extreme" senators - the 25 most conservative and the 25 most liberal members in each Senate. On "moderate" senators, the results were notably poorer (as low as $52 \%$ accuracy). Moreover, there was considerable overlap between the training and testing portions of Diermeier et al's dataset, since they extracted content from multiple Senates (101st to 108th) and since members of Congress tend to preserve their beliefs over time. Specifically, 44 of the 50 "extreme" Senators in their test set were also represented in the training data, which means that the classifier was already trained on speeches made by these particular individuals. Thus the classifier might be learning to discern speaking styles rather than ideological perspectives.

Later work by the same authors (Yu et al 2008) made no distinction between moderates and extremes; rather, they tried to classify all members of the 2005 U.S. Congress by party affiliation, achieving an accuracy of $80.1 \%$ on the House of Representatives and $86.0 \%$ on the Senate. The goal of their study was to examine the personand time-dependency of the classifier by using speeches from both the Senate and the House and comparing the results. They found that party classifiers trained on House speeches could be generalized to Senate speeches of the same year, but not vice versa. They also observed that classifiers trained on House speeches performed better on Senate speeches from recent years than older ones, which indicates the classifiers' time-dependency.

We began the present work to see whether these kinds of bag-of-words SVM classification methods would hold up in analysis of speech in the Canadian Parliament (section 3 below). Our results, however, led us to question whether vocabulary differences between parties really reflected ideology or whether they had more to do with each party's role in the Parliament, and we investigate this in section 4 below.

\section{Background: The Canadian party system and Parliament}

The Canadian Parliament is a Westminster-style parliament. The party with the most seats in the House of Commons (albeit possibly a minority of them) forms the government; the other parties are the opposition. There may also be a few Independent 
(unaffiliated) members. In the last 12 years, there have been four or five parties in each Parliament. In broad terms the parties may be classified as conservative (Reform Party, Canadian Reform Conservative Alliance, Progressive Conservative Party, Conservative Party of Canada), liberal or centre (Liberal Party), ${ }^{1}$ or left-wing (New Democratic Party and Bloc Québécois).

Both English and French are official languages of Canada. A speaker in Parliament may use either language, and will sometimes even switch between the two within a speech. Everything said in Parliament is professionally translated into the other official language, and the proceedings are published in both languages. Thus the published English text of the debates is a mixture of original English and translations from French, and the French text has the complementary distribution.

\section{First set of experiments: Classifying by party}

The present work was intended as a prelude to a larger project on ideological analysis of text. Our first task, intended as a baseline, was to apply bag-of-words supportvector machine classification, as used by Diermeier et al (2007) and Yu et al (2008) on U.S. Congressional speech, to speech in the Canadian Parliament, to see whether we could classify the speech by party affiliation (as a proxy for ideology) and obtain similar results, despite the differences in the political systems of the two countries.

In Canadian politics, unlike those of the U.S., party discipline is strong and (with only rare exceptions) all members of a party will vote the same way. The governing party will always vote to support its legislation; an opposition party might oppose it or support it. Thus (in contrast to the tasks described by Diermeier et al and $\mathrm{Yu}$ et al), there is no meaningful distinction between predicting voting records from parliamentary speech and predicting party affiliation. On one hand, it might be argued that this makes the task easier because parliamentary speech is likely to be highly partisan. On the other hand, it might be argued that it makes the task more difficult, because there is a greater diversity of views with precisely the same voting pattern, and so the classification is less straightforward.

In order to avoid the problems inherent in cross-time analysis, as highlighted by the work of Diermeier et al (2007), we focus in this section on a single time period, so that there is a one-to-one mapping between members of Parliament (MPs) and documents in our dataset. Each document is a concatenation of all the speeches made by a speaker, and no other document contains text spoken by that person. Thus no speaker appears in both training and test data.

\subsection{Data}

We used both the English and French House of Commons Debates ("Hansard") for the first 350 sitting days of the 36th Parliament (1997-09-22 to 2000-05-10). In the 36th Parliament, a majority government was formed by the Liberal Party, led by Jean Chrétien. This data was available in a convenient plain-text form with sentence breaks identified (Germann 2001), as it has been widely used for research in machine translation.

\footnotetext{
1 Thus in our data, all liberals are Liberals, but not all conservatives are Conservatives. Similarly, we distinguish between opposition parties - any party that is not the governing party - and the Opposition party - the opposition party from which the Leader of the Opposition is drawn.
} 
We considered two sections of the proceedings: the debates on legislation and other statements by members ("Government Orders") and the oral question period. And we focused on the governing Liberal Party and the opposition conservative parties, ${ }^{2}$ in order to do a binary discrimination, liberal versus conservative; the left-wing parties had relatively few members in this Parliament and were excluded from the analysis.

For each MP who was a member of one of the liberal or conservative parties, and for each language, we formed a 'document' by concatenating all their utterances in debates, question period, or both throughout the Parliament. (For simplicity, we will refer to all utterances as 'speeches', regardless of their length, including questions and answers in the oral question period.) We experimented with a variety of preprocessing methods, including stemming the words or leaving them whole, removing or retaining stopwords (defined as the 500 most frequent words in the text), and removing or retaining rare words (defined as those occurring in fewer than five documents). (Details of these and other pre-processing matters are given by Riabinin 2009.) In some of our experiments, we discarded the data for members who said very little, or nothing at all, in question period or in debates, using 200 documents representing 121 liberals and 79 conservatives; in other experiments, we considered all 156 liberal and 79 conservative members who spoke at all. ${ }^{3}$ In all, depending on our choices in pre-processing, we had about 4 million words in each language for liberals (of which approximately 900,000 were from the question periods) and 2.7 million for conservatives (of which approximately 500,000 were from the question periods).

Generally, these variations in pre-processing made little difference to the results. In this paper we report results for experiments on the texts for all speakers, with words left unstemmed and with rare words removed, which usually, though not invariably, gave the best results.

\subsection{Method}

Taking word-types as the features for classification - that is, regarding the document for each speaker as a bag of words - for each language we trained an SVM classifier for ideology as indicated by party membership, liberal or conservative. In training and testing, we used five-fold cross-validation. We experimented with four weighting schemes: boolean (presence of feature), tf (term frequency), tf-norm (term frequency normalized by document length), and tf-idf (term frequency by inverse document frequency). The best results were obtained with $t f$-norm and $t f-i d f$; the results we present below all use the latter.

\subsection{Results}

Table 1 shows the accuracy of classification of party membership by the SVM for each language on the documents of each data set: oral question period (OQP), debates (GOV), and the two combined (OQP+GOV). In all cases, retaining the 500 most frequent features led to higher accuracy than removing them. The baseline method of choosing the larger class (liberal) for all members would give an accuracy of $65.5 \%$. All our results are well above this baseline, and in fact reach almost $97 \%$ for oral

\footnotetext{
${ }^{2}$ At the time of this Parliament, the conservative parties were in disarray. The Opposition was the conservative Reform Party (which became the Canadian Reform Conservative Alliance in March 2000), but the conservative Progressive Conservative Party also held a number of seats.

${ }^{3}$ Several members of the conservative parties either defected to the Liberal party or became independents during this Parliament; and one member of the left-wing NDP defected to a conservative party. We treated all these members as conservatives in our experiments; for details and rationale, see Riabinin 2009.
} 
question period in English when frequent words are retained. The reason for the discrepancy between this result and the $89.5 \%$ obtained for the same data in French is unclear, as the two texts are mutual translations and no such effect was seen with the debates texts. We also observe that in three cases out of four, combining debates and question period in a single classifier is deleterious to accuracy compared to classifying each separately. Generally speaking, our results are similar to, or better than, those of Yu et al (2008) on the U.S. Congress.

Table 1. Accuracy (\%) of classification by ideology on speech in the oral question period (OQP) and debates (GOV) by liberal and conservative members of the 36th Parliament, with and without removal of the 500 most frequent features (majority baseline $=65.5 \%$ ).

\begin{tabular}{|c|c|c|c|}
\hline & OQP+GOV & OQP & GOV \\
\hline \multicolumn{4}{|c|}{ With 500 most frequent features retained } \\
\hline English & 83.8 & 96.9 & 83.3 \\
\hline French & 83.2 & 89.5 & 86.0 \\
\hline \multicolumn{4}{|c|}{ With 500 most frequent features removed } \\
\hline English & 78.7 & 92.9 & 79.6 \\
\hline French & 80.8 & 84.8 & 83.5 \\
\hline
\end{tabular}

\subsection{Discussion}

The higher accuracy of classification for question period than for debates suggests that the language of question period is in some way more partisan than that of debates. However, our examination of the most discriminative words suggests that this partisanship is not so much ideological as a matter of attack and defence. In particular, in the Canadian Parliament, the oral question period consists largely of hostile questions from members of the opposition parties to ministers of the government, with only occasional friendly questions from government backbenchers, which themselves often serve primarily to set up an attack on the opposition. ${ }^{4}$ It's possible, therefore, that our classifier may be learning - at least in part - not to distinguish ideologies but to distinguish questions from answers or attack from defence, which is not the goal of our research. Table 2 shows the ten most discriminative English words for each side in question period. For the governing liberals, the top words are hon and member, as in the hon. member for Halifax West, which is how a minister from the governing party typically addresses a member who has asked a question. Also, the word we might be used by a minister to speak on behalf of the entire party or government when responding to questions. For the opposition conservatives, the word why serves the obvious purpose of posing a question, and the words he and her are likely used to refer to government ministers who are the targets of the questioning. Also, observe the use of words such as bloc, reform, and opposite by the liberals, and prime (as in Prime Minister) and liberal and liberals by the conservatives. ${ }^{5}$ This lends further support to the hypothesis that the classifier is partially learning to distinguish government members from opposition members.

\footnotetext{
${ }^{4}$ This contrasts with the practice in similar Parliaments, such as those of Australia and the U.K., in which questions are more evenly balanced between those of the opposition and those of government backbenchers.

5 Interestingly, this tendency for the names of opponents to be discriminating features is the converse of what Lin et al (2006) found in their analysis of an Israeli-Palestinian debate, in which naming one's own side was discriminating.
} 
Table 2. The top 10 English words characterizing each class in the oral question period.

\begin{tabular}{rll}
\hline Rank & $\begin{array}{l}\text { liberal } \\
\text { (government) }\end{array}$ & $\begin{array}{l}\text { conservative } \\
\text { (opposition) }\end{array}$ \\
\hline 1 & hon & prime \\
2 & member & why \\
3 & we & liberal \\
4 & opposite & solicitor \\
5 & quebec & farmers \\
6 & housing & finance \\
7 & bloc & he \\
8 & reform & liberals \\
9 & québécois & hrdc $^{a}$ \\
10 & women & banks $^{2}$ \\
\hline
\end{tabular}

${ }^{a} H R D C=$ Human Resources Development Canada, a federal government department.

When frequent words are removed we see this effect less, with a corresponding drop in accuracy (see the second part of table 1), but it does not disappear entirely. In this condition, we certainly see reflections of ideology in vocabulary. The liberal lexicon is characterized by words related to Québec (French, Francophonie, MAl [Montréal Arts Interculturels], PQ [Parti Québécois]) and various social issues (housing, violence, humanitarian, youth, society, technology), while the conservatives tend to focus on monetary concerns (APEC, taxpayer, dollar, millions, paying, premiums), aboriginal affairs (native, Indian, chief), and, to a lesser degree, national defence (military, marshall). Nonetheless, the governing liberals use language that is generally positive (congratulate, excellent, progress) and is intended to create the appearance of a government at work (established, inform, improve, assist, developing, promote). In contrast, the opposition conservatives use negative words that are meant to call the government's competence into question (justify, resign, failed, admit, refusing, mismanage). So again, it seems that many of the features relate not to ideology but to attack and defence - not to the party's beliefs but to its status as government or opposition.

\section{Second set of experiments: Classifying by party status}

Even if a classifier for political speech were truly using features related to ideology, we would expect that at least some of these features would specifically pertain to views of current events and therefore, if it is trained on one Parliament, it will not perform as well on a different Parliament in which different events are current, as in the results of Diermeier et al discussed in section 1 above. Nonetheless, we would expect that many of the features will be invariant over time and that such a classifier will still perform much better than a baseline.

On the other hand, if the 'ideological' classifier is in reality using (solely or primarily) features related to government and opposition status, then training on one Parliament would carry over only to other Parliaments in which the parties hold the same status; if they swap roles, then the classifier will fail. Indeed, in such a case it might (or should!) perform worse than the majority baseline, tending to classify liberals as conservatives and vice versa. In our second set of experiments, we tested the hypothesis that the latter is the case - that an SVM bag-of-words classifier for Canadian parliamentary 
speech is primarily sensitive to party status, not ideology. We also looked at the inbetween case: training an 'ideological' classifier on data in which all combinations of ideology and party status are present.

\subsection{Data}

To test our hypothesis, we needed a Parliament in which, in contrast to the 36th Parliament, a conservative party was in government. We chose the recent 39th Parliament (2006-04-03 to 2008-09-07), with a minority Conservative Party ${ }^{6,7}$ government led by Stephen Harper; the Liberal party was in opposition, along with the New Democratic Party and the Bloc Québécois. The proceedings were downloaded from the Parliament of Canada website in HTML-formatted documents and processed into a format similar to that of the 36th Parliament data.

\subsection{Method and results}

\subsubsection{Replication of the first experiments on the new data}

We first replicated the experiments of section 3 on the new data, discriminating liberal members from conservative members (there was sufficient data for 104 liberals and 130 conservatives) within the same Parliament. Training and testing with five-fold cross-validation on the 39th Parliament, we achieved results similar to those of the 36th Parliament, albeit with slightly lower accuracy, especially for the English OQP documents; see table 3 and compare table 1. In particular, the accuracy of the classification on French text of speakers in Government Orders is anomalously low (baseline level) compared to all our other results including those for the English translation of the same text; we have no explanation for this. We also observe that for this data, unlike the 36th Parliament, the strategy of removing the 500 most frequent words is sometimes superior to that of retaining them.

Table 3. Accuracy (\%) of classification by ideology on the 39th Parliament, with and without the 500 most frequent words retained (majority baseline $=55.8 \%$ ).

\begin{tabular}{|c|c|c|c|}
\hline & OQP+GOV & OQP & GOV \\
\hline \multicolumn{4}{|c|}{ With 500 most frequent features retained } \\
\hline English & 83.8 & 88.3 & 72.3 \\
\hline French & 75.5 & 88.8 & 56.8 \\
\hline \multicolumn{4}{|c|}{ With 500 most frequent features removed } \\
\hline English & 79.9 & 83.5 & 73.2 \\
\hline French & 79.0 & 88.2 & 57.2 \\
\hline
\end{tabular}

Examining the primary features used in the classification for oral question periods, we observed that several words "swapped sides": four of the top 10 English words that characterized the liberals in the 36th Parliament characterized conservatives in the 39th Parliament, and the primary word that characterized conservatives in the 36th Parliament was the second word that characterized liberals in the 39th; see table 4. This is evidence for our hypothesis that the classifier is really picking up features related to government and opposition status.

\footnotetext{
${ }^{6}$ So in this Parliament, unlike the 36th, all conservatives are Conservatives.

${ }^{7}$ http://www2.parl.gc.ca/housechamberbusiness/ChamberSittings.aspx
} 
Table 4. The top 10 English words characterizing each class in oral question periods in each Parliament (extending table 2). Boldface indicates words that "swap sides" between the two Parliaments. Boldface italic words characterize the governing side; the boldface roman word characterizes the opposition.

\begin{tabular}{|c|c|c|c|c|}
\hline \multirow[b]{2}{*}{ Rank } & \multicolumn{2}{|c|}{ 36th Parliament } & \multicolumn{2}{|c|}{ 39th Parliament } \\
\hline & $\begin{array}{l}\text { liberal } \\
\text { (government) }\end{array}$ & $\begin{array}{l}\text { conservative } \\
\text { (opposition) }\end{array}$ & $\begin{array}{l}\text { liberal } \\
\text { (opposition) }\end{array}$ & $\begin{array}{l}\text { conservative } \\
\text { (government) }\end{array}$ \\
\hline 1 & hon & prime & conservatives & bloc \\
\hline 2 & member & why & prime & liberals \\
\hline 3 & we & liberal & conservative & senate \\
\hline 4 & opposite & solicitor & immigration & violent \\
\hline 5 & quebec & farmers & mulroney & we \\
\hline 6 & housing & finance & kyoto & québécois \\
\hline 7 & bloc & he & admit & greenhouse \\
\hline 8 & reform & liberals & minority & ndp \\
\hline 9 & québécois & hrdc & promise & corruption \\
\hline 10 & women & banks & her & member \\
\hline
\end{tabular}

\subsubsection{Classifying across Parliaments}

Again we used the proceedings of the 36th and 39th Parliaments, both English and French, but in each language we took the classifiers trained on one Parliament and tested them on the other. (In these experiments, we have the deprecated situation that some individual speakers, being members of both parliaments, occur in both the training data and the test data and thereby might give the classifier an unfair boost.) The results, shown in table 5, are in all cases well below the majority baseline scores, just as we hypothesized; when party status changes, there are no constant ideological features to save the classifier.

Table 5. Accuracy (\%) of classification by ideology when training on one Parliament (36th or 39th) and testing on the other.

\begin{tabular}{|c|c|c|c|}
\hline $\begin{array}{c}\text { Training } \rightarrow \\
\text { Testing }\end{array}$ & OQP+GOV & OQP & GOV \\
\hline \multicolumn{4}{|c|}{$36 \rightarrow 39$ (Majority baseline $=55.8 \%)$} \\
\hline \multicolumn{4}{|c|}{ With 500 most frequent features retained } \\
\hline English & 44.9 & 43.3 & 44.6 \\
\hline French & 45.7 & 46.1 & 47.0 \\
\hline \multicolumn{4}{|c|}{ With 500 most frequent features removed } \\
\hline English & 46.2 & 44.6 & 44.1 \\
\hline French & 43.5 & 49.6 & 43.5 \\
\hline \multicolumn{4}{|c|}{$39 \rightarrow 36$ (Majority baseline $=65.5 \%$ ) } \\
\hline \multicolumn{4}{|c|}{ With 500 most frequent features retained } \\
\hline English & 36.8 & 34.5 & 36.2 \\
\hline French & 35.2 & 51.10 & 33.5 \\
\hline \multicolumn{4}{|c|}{ With 500 most frequent features removed } \\
\hline English & 35.0 & 49.6 & 42.7 \\
\hline French & 36.4 & 51.1 & 33.5 \\
\hline
\end{tabular}

We also tried training classifiers on the data of the two Parliaments combined. This dataset includes all combinations of ideology and party status - that is liberals in 
government, liberals in opposition, conservatives in government, and conservatives in opposition. Some speakers, those who were members of both Parliaments, appear with each possible party status, whereas others, those who were members of only one of the two Parliaments, appear in only one of these four conditions. A classifier trained on the former group performs at around the level of the majority baseline (table 6); one trained on the latter does better (table 7), but the results are overall below the level of the original experiments (tables 1 and 3), especially for OQP data. (The exception is that the anomalously low results for French GOV data are not seen when frequent features are retained.)

Table 6. Accuracy (\%) of classification by ideology on speakers who were members of both the 36th (liberal government) and 39th Parliament (conservative majority), with and without the 500 most frequent words retained (majority baseline $=64.0 \%$ ).

\begin{tabular}{|c|c|c|c|}
\hline & OQP+GOV & OQP & GOV \\
\hline \multicolumn{4}{|c|}{ With 500 most frequent features retained } \\
\hline English & 62.0 & 66.9 & 61.1 \\
\hline French & 63.0 & 63.0 & 63.0 \\
\hline \multicolumn{4}{|c|}{ With 500 most frequent features removed } \\
\hline English & 64.0 & 66.9 & 59.4 \\
\hline French & 64.0 & 64.0 & 64.0 \\
\hline
\end{tabular}

Table 7. Accuracy (\%) of classification by ideology on speakers who were members of either the 36th (liberal government) or 39th Parliament (conservative majority), but not both, with and without the 500 most frequent words retained (majority baseline = $51.9 \%)$.

\begin{tabular}{|c|c|c|c|}
\hline & OQP+GOV & OQP & GOV \\
\hline \multicolumn{4}{|c|}{ With 500 most frequent features retained } \\
\hline English & 78.5 & 81.7 & 72.6 \\
\hline French & 76.6 & 78.3 & 71.2 \\
\hline \multicolumn{4}{|c|}{ With 500 most frequent features removed } \\
\hline English & 76.3 & 73.5 & 71.9 \\
\hline French & 75.0 & 76.1 & 61.9 \\
\hline
\end{tabular}

\subsubsection{Including the other opposition parties}

Another way to see whether the classifier is more sensitive to party status than to ideology is to muddy the ideological waters by including the left-wing parties, which were in opposition in both Parliaments, in the analysis. If the classification were truly ideological, lumping these parties in with the other conservative (36th Parliament) or liberal (39th Parliament) opposition parties would markedly degrade the performance of the classifier. On the other hand, if party status is what matters, there should be little effect in doing so as the opposition parties will be more or less indistinguishable. We carried out this experiment on the English data with frequent words retained. ${ }^{8}$

The results are shown in table 8. They should be compared with the liberal / conservative results for the same Parliament and same processing method, shown in the first lines of table $1(96.9 \%, 83.3 \%)$ and table $3(88.3 \%, 72.3 \%)$. There is almost no degradation of performance on the 36th Parliament; for the 39th Parliament, there is a

\footnotetext{
${ }^{8}$ We have not yet completed these experiments for other conditions, for the French texts, or for the OQP+GOV English texts.
} 
noticeable drop (10.12 percentage points) for the question period, but little for the debates.

Table 8. Accuracy (\%) of classification of government and opposition (all parties) on English text of the 36th and 39th Parliaments with the 500 most frequent words retained (majority baselines $=51.5 \%$ and $59.4 \%$ respectively).

\begin{tabular}{lll}
\hline & OQP & GOV \\
\hline 36th & 95.6 & 82.6 \\
39th & 78.2 & 70.9 \\
\hline
\end{tabular}

\subsection{Discussion}

The results seen in sections 4.2.1-3 are consistent with the hypothesis that the SVM bag-of-words classifier is sensitive not to expressions of ideology for which party membership is a reasonable proxy, but rather to expressions of attack and defence, opposition and government. When we train on one parliament and test on another in which party roles have been interchanged, the performance of the classifier completely disintegrates; the degradation is far worse than can be explained merely by the difference between the two parliaments in the vocabulary of the current topics of discussion. Some features that are indicative of each party "swap sides" with the change of government. And combining ideologically inconsistent opposition parties in the classifier does not in most cases seriously degrade its performance.

\section{Classification based on the emotional content of speeches}

Recall that our feature analysis of the 36th Parliament showed that liberal members tended to use words that convey a more positive sentiment than those used by conservatives. This suggests that it might be possible to distinguish parties or ideologies (solely) by the emotional content of their speeches. Indeed, researchers such as James Pennebaker have made something of an industry of interpreting politicians from a statistical analysis of their use of a single category of words. For example, during the 2008 U.S. presidential election, Pennebaker (2008) wrote:

Over the last few years, some have argued that the use of negations (e.g., no, not, never) indicate [sic] a sign of inhibition or constraint. Low use of negations may be linked to impulsiveness. ... Across the election cycle, Obama has consistently been the highest user of negations - suggesting a restrained approach — where as [sic] McCain has been the lowest - a more impulsive way of dealing with the world.

Similarly, Pennebaker concluded that McCain's greater use than Obama of the firstperson singular $(I, m e, m y)$ signalled a likely greater openness and honesty. ${ }^{9}$

In the context of our results above, the questions we ask are not just whether liberals can be distinguished from conservatives in the Canadian Parliament merely by the emotional content of their speeches, but also, if so, whether the feature actually discriminates ideology (in line with the stereotype of happy liberals, dour conservatives) or is again confounded by the parties' status in the Parliament.

\footnotetext{
${ }^{9}$ The validity of this kind of analysis is discussed and defended by Pennebaker et al (2007a). But Pennebaker (2008) also writes: "No one should take any text analysis expert's opinions too seriously. The art of computer-based language analysis is in its infancy. We are better than tea-leaf readers but probably not much."
} 


\subsection{Method and data}

To test these questions, we used Pennebaker et al's (2007b) software Linguistic Inquiry and Word Count (LIWC2007). LIWC counts the proportion in a text of particular words and word stems in over 60 categories, including linguistic properties (pronouns, adverbs, prepositions, etc), psychological denotation (positive emotion, negative emotion, etc), and various topics (work, money, religion, etc); it does not, itself, provide any interpretation of the counts.

For these experiments, we used the English speeches of the oral question periods and debates of the 36th and 39th Parliaments, excluding MPs who spoke very little. This gave us a dataset of documents for 200 MPs (121 liberals, 79 conservatives) in the 36th Parliament and 220 MPs (125 conservatives and 95 liberals) in the 39th Parliament. First, we ran LIWC on this data, which gave us a 64-component vector for each document, each component being the value that LIWC computed for the document for one of its categories. We then performed classification experiments on the data (with five-fold cross-validation) using this 64-component representation of the documents, in order to see whether positive and negative emotion were among the top discriminating features for liberals and conservatives, respectively. Then we repeated the classification, using only positive emotion and negative emotion (referred to as POSEMO and NEGEMO) as features. Finally, we performed a third experiment, in which affect was reduced to a single feature, the amount by which the positive emotion in the text exceeded the negative (i.e., POSEMO minus NEGEMO); this representation doesn't distinguish a completely unemotional text from one that contains emotion of each polarity in equal amounts.

\subsection{Results}

Table 9 shows the results of these experiments. In the first experiment, with 64 features, the accuracy for both datasets was equal to the majority baseline, because all MPs were classified as members of the majority party! In contrast, using only POSEMO and NEGEMO, either as two features or as a single feature, yielded a substantial improvement of up to 20.5 percentage points over the baseline (a relative error reduction of $51.9 \%$ ) for the 36th Parliament and 16.3 points for the oral question periods of the 39th. However, performance remained around baseline for the debates of the 39th Parliament.

Table 9. Accuracy (\%) of classification by party using LIWC features for English text of the 36th and 39th Parliaments' oral question period (OQP) and debates (GOV) (majority baseline $=60.5 \%$ and $56.8 \%$ respectively).

\begin{tabular}{lcccc}
\hline & \multicolumn{2}{c}{36 th } & \multicolumn{2}{c}{39 th } \\
& OQP & GOV & OQP & GOV \\
\hline 64 features & 60.5 & 60.5 & 56.8 & 56.8 \\
POSEMO and NEGEMO & 80.5 & 79.5 & 73.1 & 55.0 \\
POSEMO minuS NEGEMO & 81.0 & 78.5 & 72.2 & 59.1 \\
\hline
\end{tabular}

Nonetheless, a feature analysis confirmed that in the 36th Parliament, positive emotion was among the top five liberal features and negative emotion was among the top ten conservative features, whereas in the 39th Parliament, positive emotion was the fourth feature for conservatives in oral question periods and sixth in debates, whereas negative emotion was eighth and tenth respectively for liberals. Hence, we can see that positive emotion is a characteristic of members of the governing party, and negative emotion is a characteristic of members of an opposition party; again, party 
status confounds ideological classification. The result of the classifier on all 64 features may be explained by the fact that no LIWC category had a significant impact on the classification. In other words, even though some LIWC categories were discriminating features for liberals and others were discriminating features for conservatives, the overall difference between the two groups was so slight that without feature selection the resulting classifier simply labelled all test instances as belonging to the majority class. This seems to be the case also for POSEMO and NEGEMO by themselves in debates in the 39th Parliament.

\section{Conclusion}

Our results cast doubt on the results of research that uses words as features in classifying the ideology of speech in legislative settings - and possibly in political speech more generally. Rather, the language of attack and defence, of government and opposition, seems to dominate and confound any sensitivity to ideology. Such research therefore reduces in effect to the classification of support or opposition, much as in the linguistic component of the work of Thomas et al (2006) described in section 1 above. However, even if our classifiers are construed as distinguishing support from opposition, our results are much more accurate than those of Thomas et al, even though we did not use any explicit component for detecting agreement or disagreement between individual speakers. This may be partly attributed to one of the differences between Canadian and U.S. politics: Canadian parties have strong party discipline, and agreement between speakers may be reliably inferred from shared party membership.

Our results contrast with the conclusions of Diermeier et al (2007), who argue from their own results that speakers' words in debates in the U.S. Congress are "expressions or representations of an underlying belief system". Again, political differences might be a partial explanation of the difference. Perhaps the weak party discipline of the U.S. and the separation of the Congress from the Executive branch motivates greater attention to ideological substance in debates than does the Canadian (Westminster-style) system in which an explicit governing party, including the head of government and all cabinet ministers, is represented as such in the legislature. But this is speculation; our results have demonstrated a confound that must be taken into account in research on ideological classification of speech in any context.

\section{References}

Diermeier, Daniel; Godbout, Jean-François; Yu, Bei; and Kaufmann, Stefan (2007). Language and ideology in Congress. Annual Meeting of the Midwest Political Science Association.

Germann, Ulrich (2001). Aligned Hansards of the 36th Parliament of Canada. Available at www.isi.edu/naturallanguage/download/hansard/

Greene, Stephan (2007). Spin: Lexical Semantics, Transitivity, and the Identification of Implicit Sentiment. PhD thesis, University of Maryland, College Park.

Jiang, Maojin and Argamon, Shlomo (2008). Political leaning categorization by exploring subjectivities in political blogs. Proceedings, 4th International Conference on Data Mining (DMIN 2008), pp 647-653.

Lin, Wei-Hao; Wilson, Theresa; Wiebe, Janyce; and Hauptmann, Alexander (2006). Which side are you on? Identifying perspectives at the document and sentence levels. Proceedings of the 10th Conference on Natural Language Learning (CoNLL-X), pp 109-116.

Mullen, Tony and Malouf, Robert (2006). A preliminary investigation into sentiment analysis of informal political discourse. Proceedings of the AAAI Symposium on Computational Approaches to Analysing Weblogs (AAAICAAW), pp. 159-162.

Pennebaker, James W. (2008). The meaning of words: Obama versus McCain. Weblog, 12 October 2008. Available at wordwatchers. wordpress.com/2008/10/12/

Pennebaker, James W.; Chung, Cindy K.; Ireland, Molly; Gonzales, Amy; and Booth, Roger J. (2007a). The development and psychometric properties of LIWC2007. Available at www.liwc.net/ LIWC2007LanguageManual.pdf

Pennebaker, James W.; Chung, Cindy K.; Ireland, Molly; Gonzales, Amy; and Booth, Roger J. (2007b). Linguistic Inquiry and Word Count (LIWC2007). Available at www.liwc.net 
Riabinin, Yaroslav (2009). Computational identification of ideology in text: A study of Canadian parliamentary debates. MSc paper, Department of Computer Science, University of Toronto, January 2009. Available at www.cs.toronto.edu/compling/publications.html

Thomas, Matt; Pang, Bo; and Lee, Lillian (2006). Get out the vote: Determining support or opposition from Congressional floor-debate transcripts. Proceedings of the Conference on Empirical Methods in Natural Language Processing (EMNLP 2006), pp. 327-335.

Yu, Bei; Kaufmann, Stefan; and Diermeier, Daniel (2008). Classifying party affiliation from political speech. Journal of Information Technology in Politics, 5(1), 33-48. 